\title{
Pre- and Postinfection Activity of Fungicides in Control of Hop Downy Mildew
}

David H. Gent, United States Department of Agriculture-Agricultural Research Service, Forage Seed and Cereal Research Unit, and Department of Botany and Plant Pathology, Oregon State University, Corvallis 97331; and Megan C. Twomey, Sierra N. Wolfenbarger, and Joanna L. Woods, Department of Botany and Plant Pathology, Oregon State University, Corvallis

\begin{abstract}
Gent, D. H., Twomey, M. C., Wolfenbarger, S. N., and Woods, J. L. 2015. Pre- and postinfection activity of fungicides in control of hop downy mildew. Plant Dis. 99:858-865.

Optimum timing and use of fungicides for disease control are improved by an understanding of the characteristics of fungicide physical mode of action. Greenhouse and field experiments were conducted to quantify and model the duration of pre- and postinfection activity of fungicides most commonly used for control of hop downy mildew (caused by Pseudoperonospora humuli). In greenhouse experiments, control of downy mildew on leaves was similar among fungicides tested when applied preventatively but varied depending on both the fungicide and the timing of application postinfection. Disease control decreased as applications of copper were made later after inoculation. In contrast, cymoxanil, trifloxystrobin, and dimethomorph reduced disease with similar efficacy when applied $48 \mathrm{~h}$ after inoculation compared with preventative applications of these fungicides. When fungicides were applied $72 \mathrm{~h}$ after inoculation, only dimethomorph reduced the sporulating leaf area similarly to preinoculation application timing. Adaxial chlorosis, necrosis, and water soaking of inoculated leaves, indicative of infection by $P$. humuli, were more severe when plants were treated with cymoxanil, trifloxystrobin, and dimethomorph 48 to $72 \mathrm{~h}$ after inoculation, even

though sporulation was suppressed. Trifloxystrobin and dimethomorph applied $72 \mathrm{~h}$ after inoculation suppressed formation of sporangia on sporangiophores as compared with all other treatments. In field studies, dimethomorph, fosetyl-Al, and trifloxystrobin suppressed development of shoots with systemic downy mildew to the greatest extent when applied near the timing of inoculation, although the duration of preventative and postinfection activity varied among the fungicides. There was a small reduction in efficacy of disease control when fosetyl-Al was applied 6 to 7 days after inoculation as compared with protective applications. Trifloxystrobin had 4 to 5 days of preinfection activity and limited postinfection activity. Dimethomorph had the longest duration of protective activity. Percent disease control was reduced progressively with increasing time between inoculation and application of dimethomorph. These findings provide guidance to the use of fungicides when applications are timed with forecasted or post hoc disease hazard warnings, as well as guidance on tank-mixes of fungicides that may be suitable both for resistance management considerations and extending intervals between applications.
\end{abstract}

Physical mode of action of a fungicide refers to the observable effects of a compounds on a disease with respect to placement and timing when applied before infection, after infection, or after symptom development (33). The concept also includes other characteristics of the fungicide that may affect disease control such as retention and vapor activity. Optimum timing and use of fungicides for disease control is improved by an understanding of physical mode of action. This is imperative when a disease warning system is used as an aid in timing fungicide applications (27). Given the logistics of responding to a disease warning farm-wide, linking quantitative information on the degree and duration of fungicide effectiveness is helpful for making warning systems more useful in practice.

Downy mildew (caused by Pseudoperonospora humuli) is among the most important diseases of hop in the majority of production regions in the northern hemisphere $(20,30)$. The potential for both indirect and direct damage to yield and cone quality exposes growers to the risk of complete crop failures if the disease is unmanaged. The pathogen may cause local and systemic infections of aboveground tissues, rhizomes, and crown buds $(7-9,30)$. Crop damage may occur due to systemic shoot

Corresponding author: D. H. Gent; E-mail: gentd@onid.orst.edu

Mention of a trademark, proprietary product, or vendor does not constitute a guarantee or warranty of the product by the United States Department of Agriculture and does not imply its approval to the exclusion of the products or vendors that may also be suitable.

*The $\boldsymbol{e}$-Xtra logo stands for "electronic extra" and indicates that three supplementary figures are published online.

Accepted for publication 2 January 2015.

http://dx.doi.org/10.1094/PDIS-10-14-1004-RE

This article is in the public domain and not copyrightable. It may be freely reprinted with customary crediting of the source. The American Phytopathological Society, 2015. infections which prevent shoots from climbing and developing, loss of cone-bearing lateral branches, direct infection of cones, and, in some susceptible cultivars, a progressive death of the root system (30,31). Chronic infection of plants also may reduce plant vigor because of more rapid loss of carbohydrate reserves during autumn and winter (7). Perennial infection of plants may lead to polyetic epidemics $(12,18)$.

Fungicides are a central component of management systems for downy mildew. Disease management has become more complicated due to development of resistance to phenylamide fungicides $(11,21)$ and reduced sensitivity to phosphonate fungicides (25). Consequently, phenylamide fungicides are essentially not used in regions where resistance is prevalent, and higher rates of phosphonate products are now required to achieve satisfactory disease control. Disease management also utilizes fungicides belonging to multiple other groups, including cyanoacetamideoxime, carboxylic acid amides, quinone outside inhibitors, and copper formulations. Currently, the disease necessitates repeated fungicide applications and, on average, 5.7 fungicide applications are made for downy mildew in established hop yards in Oregon (14), although 10 applications or more may be made on highly susceptible cultivars (12).

Given the central role that fungicides play in disease management, there are surprisingly few data on the duration of pre- and postinfection activity of the various modes of action for hop downy mildew. In other diseases caused by oomycetes such Phytophthora infestans (19), cymoxanil tends to have short-lived preventative activity because of rapid metabolism in plants, although cymoxanil may provide up to $48 \mathrm{~h}$ of postinfection disease control. Pre- and postinfection activity of fungicides in the carboxylic acid amide group appears to be variable, depending on the pathosystem. Six to 9 days of protection were reported against potato late blight ( $P$. infestans) and cucumber downy mildew (Pseudoperonospora cubensis) by dimethomorph $(3,15,19)$. Carboxylic acid amide fungicides typically provide 24 to $48 \mathrm{~h}$ of postinfection activity against oomycete pathogens $(6,16)$, although certain carboxylic acid amide fungicides also may reduce sporulation when applied after infection. Postinfection activity of fungicides in the quinone outside inhibitors group appears limited to approximately 12 to $24 \mathrm{~h}$, with longer periods of suppression reported occasionally 
$(28,32,35)$. Suppression of sporulation by these fungicides is documented in some downy mildew pathogens (35). Phosphonate fungicides have preinfection and postinfection activity that vary markedly among downy mildew diseases. Estimates of postinfection activity among phosphonate fungicides ranges from $48 \mathrm{~h}$ to greater than 14 days $(22,34)$. Impaired sporulation is reported in several downy mildew pathogens following postinfection application of phosphonate fungicides $(4,22)$. Copper fungicides generally are thought to control downy mildew diseases only when applied before infection (15).

In this research, we quantified the postinfection activity of fungicides most commonly used for control of hop downy mildew and described the duration of disease control under field conditions. This information is of central importance in making strategic decisions on fungicide selection, particularly when fungicide application decisions are linked to disease hazard warnings $(12,13)$.

\section{Materials and Methods}

Plant material. Plants of the downy-mildew-susceptible cultivar Pacific Gem were propagated from soft wood cuttings and maintained in a greenhouse devoid of downy mildew. The greenhouse was maintained at 20 to $25^{\circ} \mathrm{C}$ with a 14 -h photoperiod. Plants were grown in Sunshine Mix number 1 (SunGro Horticulture, Bellevue, WA) in $820-\mathrm{cm}^{3}$ pots for approximately 21 days. Plants were watered regularly and supplied with Champion 17-17-17 $\left(\mathrm{N}_{-} \mathrm{P}_{2} \mathrm{O}_{5^{-}}\right.$ $\mathrm{K}_{2} \mathrm{O}$ ) fertilizer with miconutrients (McConkey's, Portland, OR) at each irrigation to promote vigorous growth.

Greenhouse experiments. Fungicides registered for use on hop in the United States and commonly used in the management of downy mildew were evaluated for pre- and postinfection efficacy in greenhouse experiments. (The greenhouse used for these experiments was different than the greenhouse used for plant propagation.) The fungicides evaluated were dimethomorph (Forum; BASF Corp., Research Triangle Park, NC), cymoxanil (Curzate 60DF; DuPont, Wilmington, DE), fosetyl-Al (Aliette WDG; Bayer CropScience, Research Triangle Park, NC), copper hydroxide (Kocide 2000; DuPont), and trifloxystrobin (Flint; Bayer CropScience). In these experiments, fungicides were applied to greenhouse-grown plants of Pacific Gem at six time points: $24 \mathrm{~h}$ before inoculation and $6,12,24,48$, and $72 \mathrm{~h}$ after inoculation. Fungicide rates were calculated as a concentration based on the maximum rates allowable on the current manufacturers' label and assuming an application volume of 935 liters of water per hectare. The concentrations were dimethomorph at $0.204 \mu \mathrm{l}$ a.i. $/ \mathrm{ml}$, cymoxanil at $150 \mu \mathrm{g}$ a.i. $/ \mathrm{ml}$, fosetyl-Al at $4,800 \mu \mathrm{g}$ a.i./ml, copper hydroxide at $829 \mu \mathrm{g}$ a.i./ml, and trifloxystrobin at $150 \mu \mathrm{g}$ a.i./ml. Hand-held atomizers (Nalgene, Rochester, NY) were used to apply fungicides to the abaxial surface of the leaves to just before the point of run-off. Application of the fungicides took less than $15 \mathrm{~min}$ and the spray solution dried on the leaves within minutes of application. Three plants were random selected to receive a given fungicide-timing treatment (hereafter referred to as treatment) within a replication of the experiment. There was a two-way factorial structure of the factors fungicide and timing of application. These factors were randomized in each of four replications (blocks) over time. Individual plants within a replication of the experiment were considered subsamples.

On the day of inoculation, plants were inoculated with a suspension of $P$. humuli at $5 \times 10^{4}$ sporangia/ml derived from a field population of the pathogen obtained from an experimental breeding plot in Oregon that had not been exposed to the fungicides for at least 10 years. Inoculum was maintained and harvested as described previously (23). A fine mist of inoculum was applied to the abaxial surface of the leaves using a Preval airless paint sprayer (Chicago Aerosol, Coal City, IL) to just before the point of run-off. Inoculated plants were covered with large plastic bags for $24 \mathrm{~h}$ to promote infection and then incubated in a greenhouse maintained at 20 to $25^{\circ} \mathrm{C}$ with a 14-h photoperiod for the following 7 days. Six days after inoculation, large plastic bags were misted with tap water and placed over the plants in the late afternoon (approximately 5 P.M.) to induce sporulation. The following morning, the plastic bags were removed and the percentage of leaf area bearing sporangia was assessed visually on the leaves at the third and fourth node from the top of each plant (12 leaves total per fungicide treatment), with the aid of standard area diagrams developed by the authors using Adobe Photoshop (version 13.0.1; San Jose, CA). Percent disease control relative to the nontreated was calculated as $100 \times\left(1-\left(y_{T} / y_{c}\right)\right)$, where $y_{T}$ is the severity of downy mildew in a given treatment and $y_{c}$ is the severity of downy mildew in the nontreated control in the same block of the experiment.

Differences were apparent in leaf area with sporulating downy mildew lesions and leaf area that was free of symptoms of downy mildew (Supplementary Fig. S1). To capture these differences, disease assessments were conducted based on both the percent leaf area with signs of the pathogen (i.e., bearing sporangiophores) and percent leaf area with chlorosis, necrosis, or other symptoms of previous infection.

The number of sporangia produced was assessed on the nontreated control plants and plants in the treatments that were sprayed with fungicides $72 \mathrm{~h}$ after inoculation. Sporangia were collected from the three plants receiving a given treatment by spraying a fine mist of water to the abaxial leaf surface with a Preval airless paint sprayer and collecting the rinsate into a beaker. The number of sporangia in an aliquot of the spore suspension was counted with the aid of a hemacytometer and compound microscope. At least four counts were made per treatment and averaged. The total number of sporangia per plant was calculated based on the concentration of sporangia in the aliquot and total volume of the sporangial suspension.

Field experiments. Based on the results of the greenhouse experiments and consideration of fungicides that are typically used in hop production, fosetyl-Al, dimethomorph, and trifloxystrobin were selected for further evaluation of pre- and postinfection activity for shoot infection. The basic experimental design was to grow plants free of downy mildew in an outdoor environment either in pots or planted in a field, apply fungicide treatments at varying time points before or after a single inoculation event, and determine the degree of disease control on shoots relative to nontreated plots. Experiments to accomplish this were conducted with potted plants during 2012 and 2013 and in field plots during 2013.

Potted plant experiment. In this experiment, rhizomes of the downy-mildew-susceptible cultivar Nugget (17) were obtained from a commercial hop yard that was relatively isolated from other yards and was mostly free of downy mildew during the preceding season. Two to three rhizomes were planted into 4-liter pots in a potting soil mix consisting of $20 \%$ cocoa coir, $30 \%$ composted bark, $20 \%$ peat moss, and $30 \%$ screen pumice, amended with lime and dolomite (Teufel Products, Hillsboro, OR) at $0.6 \mathrm{~kg} / \mathrm{m}^{3}$. The pots were placed on gravel beneath an uncovered greenhouse frame. The plants were watered by hand once shoots emerged to minimize wetness on foliage, and were fertilized at each watering with a 200-ppm solution of 20-10-20 fertilizer (percent nitrogen, $\mathrm{P}_{2} \mathrm{O}_{5}$, and $\mathrm{K}_{2} \mathrm{O}$, respectively). When plants were approximately 18 to $27 \mathrm{~cm}$ tall, the shoots were trimmed back to three nodes to release apical dominance and encourage development of lateral shoots. Approximately 2 weeks later (10 May 2012 and 24 April 2013), the first fungicide treatments were applied. In 2012, treatments were applied 7, 3, and 1 day before and 1, 4 , and 7 days after inoculation. In 2013, fungicide applications were made 6,4 , and 1 day before and 1,2 and 6 days after inoculation. Fungicide applications were made near the same time of day for all applications. Rates of fungicide were equivalent to fosetyl-Al at $4.48 \mathrm{~kg} / \mathrm{ha}$, trifloxystrobin at $0.07 \mathrm{~kg} / \mathrm{ha}$, and dimethomorph at $0.195 \mathrm{~kg} / \mathrm{ha}$ in an application volume of water at 468 liters/ha. If it was raining at the time the plants were to be sprayed, a plastic cover was pulled over the greenhouse frame approximately $2 \mathrm{~h}$ before the fungicide application, to dry the foliage. The plastic cover was left in place for approximately $4 \mathrm{~h}$ after the fungicide. This was necessary only in 2013 for the treatments applied 4 days after inoculation. Fungicides were applied through three single flat-fan 8002 nozzles equally spaced on a 76- $\mathrm{cm}$ boom and at a pressure of approximately $240 \mathrm{kPa}$. Nontreated, inoculated plots were included as positive controls, and nontreated, noninoculated plots were included as negative controls to determine background levels of downy mildew not resulting from the inoculation. An experimental unit consisted of 10 pots in a five-by-two rectangular arrangement. Each combination of 
fungicide and application timing was randomized within each of five blocks in a complete block design. Thus, there was a two-way factorial structure of the factors fungicide and timing of application.

On the day of inoculation, plants were spray inoculated with a suspension of $P$. humuli at $10^{5}$ sporangia $/ \mathrm{ml}$ to the point of runoff using a handheld pump sprayer (Gilmour Manufacturing Company, Somerset, PA). The inoculum was derived from the same field population used in the greenhouse experiments. After inoculation, the plants were misted intermittently until the next morning to promote shoot infection. Temperature, relative humidity, rain, and wind speed were measured at the height of the top of the shoots by a Spectrum WatchDog 700 weather station (Spectrum Technologies, Inc., Aurora, IL) (Supplementary Fig. S2). Disease density was assessed by counting the number of shoots with signs or symptoms characteristic of systemic downy mildew in each plot 21 days after inoculation. Signs and symptoms considered downy mildew were chlorosis of leaves near the shoot tip, downward cupping of leaves, and shortened internodes (20). Percent disease control was calculated similarly as described for the greenhouse experiment.

Vegetable Research Farm experiment. Plots of Nugget were established at the Oregon State University Vegetable Research Farm on 28 March 2013, with rhizomes sourced as described previously. Four to eight rhizomes (depending on the experimental block) were planted in groups (hills) spaced every $76 \mathrm{~cm}$ apart within and between rows. A plot consisted of 10 hills on a five-by-two rectangular arrangement. Plots were separated by on all sides by $1.5 \mathrm{~m}$ of bare soil to minimize plot-to-plot interference.

An application of dimethenamid (Outlook; BASF Corp.) at $0.63 \mathrm{~kg} / \mathrm{ha}$, clethodim (Select 2 EC; Valent USA Corp., Walnut Creek, CA) at $0.28 \mathrm{~kg} / \mathrm{ha}$, and crop oil (Mor-Act Crop Oil; Wilbur-Ellis Co., Fresno, CA) at 2.3 liters/ha was made on 24 April for weed control. The plots were treated with cymoxanil fungicide (Curzate $60 \mathrm{DF}$; DuPont) at $0.13 \mathrm{~kg} / \mathrm{ha}$ on 24 April, 1 May, 15 May, and 20 May to minimize the likelihood of downy mildew developing before experiments began. Plots were fertilized with 40-0-0 fertilizer at $112 \mathrm{~kg} / \mathrm{ha}$ on 30 April and 16-1616 at $56 \mathrm{~kg} / \mathrm{ha}$ on 21 May. Irrigation was applied by sprinklers as needed; typically, a single irrigation per week that delivered 1 to $3 \mathrm{~cm}$ of water.

Fungicide and application timing treatments were made as described for the 2013 potted plant experiment, except that the first application was made 7 days (rather than 6 days) before inoculation. The first applications were made on 18 June and plots were inoculated on 25 June. Inoculations and assessment of density of diseased shoots were made as described for the potted plant experiment in 2013. The plots were irrigated for $1 \mathrm{~h}$ by sprinklers after the inoculation to promote infection, in addition to $7.4 \mathrm{~mm}$ of rain that occurred in the $12 \mathrm{~h}$ following inoculation.

Data analysis. Data from the greenhouse experiments were analyzed in a mixed-effect model as a factorial. Fungicide and application timing were fixed effects and replication (block) was considered a random factor. Percent disease control was the response variable for the assessments of disease severity. Mixed-model analyses were conducted using the GLIMMIX procedure in SAS (version 9.4; SAS Institute, Cary, NC) assuming a normal distribution of the response variable. Sporulation data were analyzed directly after log transformation; a normal distribution of the response variable was specified in the generalized linear mixed model. In all analyses of greenhouse data, unequal variances were specified among treatments using the group option in GLIMMIX.

Data for each treatment from the field experiments in 2012 and 2013 were combined and standardized to percent disease control relative to the nontreated control and regressed on time (days) before or after inoculation. Percent disease control in relationship to the timing of fungicide application was expressed in a model with quadratic and cubic terms for fungicide timing. Parsimonious models with acceptable residual diagnostics were selected. Experiment, block nested within experiment, and the interaction of days $\times$ experiment were considered random factors in the analysis. Analyses were conducted by mixed-model regression using the GLIMMIX procedure.

\section{Results}

Greenhouse experiments. Inoculated control plants developed sporulating downy mildew lesions that covered, on average, $89 \%$ of the leaf area. Noninoculated control plants had $1 \%$ or less leaf area affected by downy mildew in every run of the experiment, confirming that the majority of disease was due to the inoculations and background levels of downy mildew were inconsequential.

The percent reduction in leaf area with sporulating downy mildew lesions varied depending on the fungicide $(F=336.72, P<0.0001)$, the timing of the application $(F=60.85, P<0.0001)$, and the interaction of the factors $(F=28.18, P<0.0001)$. All fungicides provided nearly complete disease control when applied $24 \mathrm{~h}$ before inoculation (Fig. 1A) but varied markedly in postinfection activity. With copper, percent disease control decreased progressively as applications were made later after inoculation. Cymoxanil, trifloxystrobin, and dimethomorph reduced disease with similar efficacy when applied $48 \mathrm{~h}$ after inoculation as compared with applications of these fungicides made before inoculation. Only dimethomorph reduced sporulating leaf area at $72 \mathrm{~h}$ after inoculation similarly to the preinoculation application timing (Fig. 1A).

The leaf area with signs of $P$. humuli or symptoms of downy mildew depended on the fungicide $(F=34.77, P<0.0001)$, timing of application, $(F=44.12, P<0.0001)$, and their interaction $(F=5.10, P<$ $0.0001)$. With some treatments, there were differences in the area bearing sporulating downy mildew lesions and leaf area with symptoms of downy mildew. This was most pronounced for trifloxystrobin and least pronounced with copper (Fig. 1B). Whereas treatment of leaves with trifloxystrobin after inoculation reduced sporulation, sporangiophores of the pathogen did develop but produced fewer sporangia than the nontreated and other fungicide treatments (Supplementary Fig. S3). Adaxial chlorosis and necrosis was associated with the abaxial leaf area bearing sporangiophores. When considering both signs of $P$. humuli and symptoms of downy mildew, all fungicide treatments had significantly poorer control when applied 48 or $72 \mathrm{~h}$ after inoculation as compared with preinoculation application timing (Fig. 1B).

Differences in sporulation were found among fungicide treatments when assessed 7 days after inoculation $(F=29.74, P<0.0001)$. Trifloxystrobin and dimethomorph significantly reduced sporulation as compared with nontreated plants (Fig. 2). With trifloxystrobin, this reduction was $0.81 \log$ units compared with nontreated plants. Plants treated with dimethomorph produced $4.0 \log$ units fewer sporangia as compared with nontreated plants.

Field experiments. Shoot infection developed in inoculated controls in the three field experiments to varying degrees. Inoculated, nontreated plots had, on average, 2.9, 3.0, and 14.7 shoots with downy mildew per plot in the experiment with potted plants in 2012 and 2013 and field experiment in 2013, respectively. Noninoculated control plots had 0.2 diseased shoots per plot in the 2012 experiment with potted plants, and none in the other two experiments (Fig. 3).

Control of downy mildew on shoots was influenced by the timing of fungicide application and was greatest when applied near to the time of inoculation (Fig. 4). Mixed models derived for percent disease control in relation to timing of application ("days") for fosetyl-Al (equation 1), trifloxystrobin (equation 2), and dimethomorph (equation 3) were:

Percent disease control $=0.7706-0.01723$ (days)

$$
-0.00348(\text { days })^{2}
$$

Percent disease control $=0.666-0.1109$ (days) $-0.00605(\text { days })^{2}$

$$
+0.002394(\text { days })^{3}
$$

Percent disease control $=0.8065-0.03139$ (days)

$$
-0.00536(\text { days })^{2}
$$

Parameter estimates were significantly different than 0 in all models at $P=0.05$, with the exception of the quadratic term in equation 1 for fosetyl-Al, which was significant at $P=0.062$ (Table 1). Disease control from fosetyl-Al was maximal when applications were made 

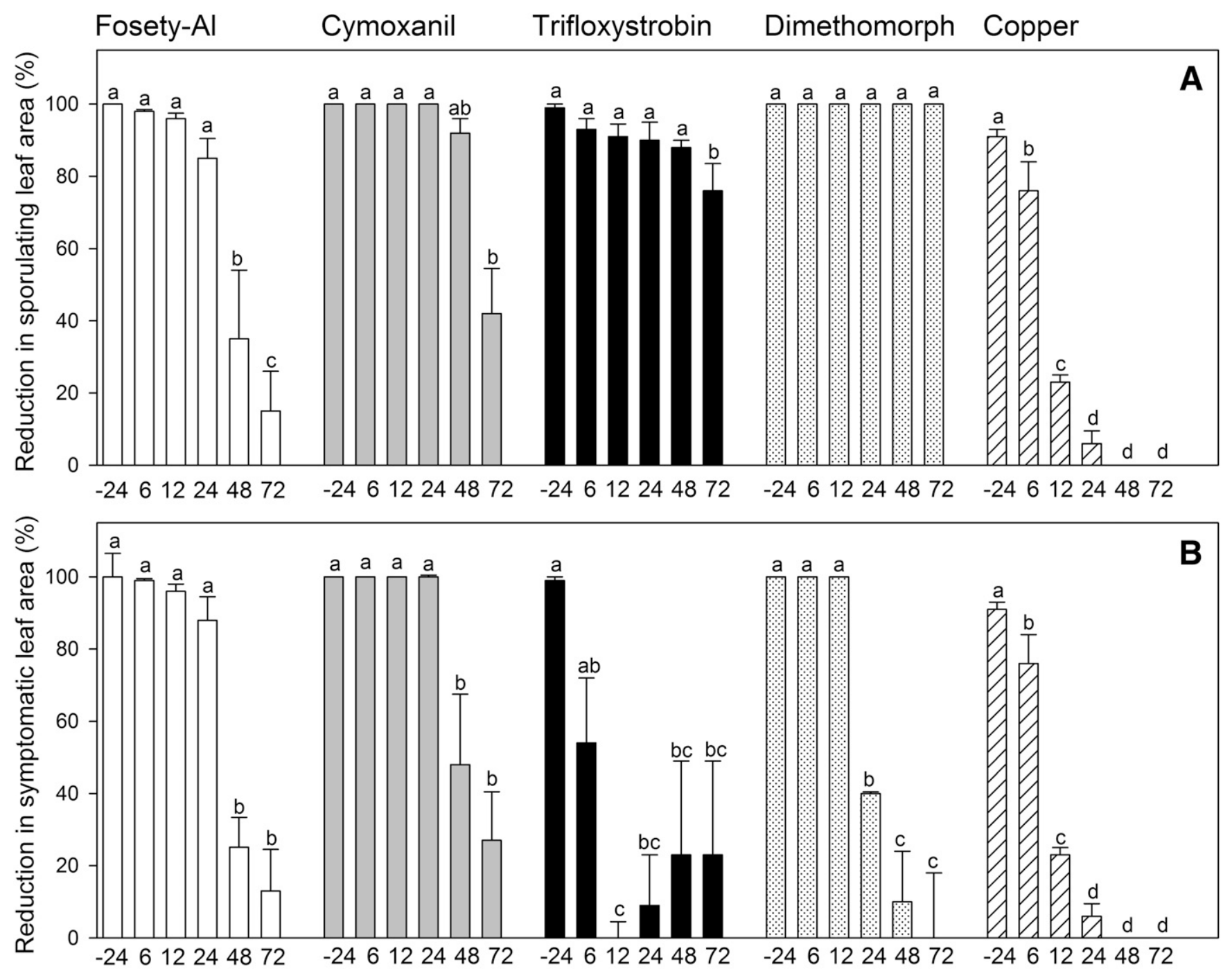

Hours before/after inoculation

Fig. 1. A, Reduction in the area of hop leaves bearing sporangiophores of Pseudoperonospora humuli and $\mathbf{B}$, signs and symptoms of downy mildew when treated with fungicides at various times before or after inoculation. Data are means and standard errors from greenhouse experiments conducted four times. Within a fungicide treatment, values sharing the same letter are statistically similar based on a mixed-model analysis $(\alpha=0.05)$.

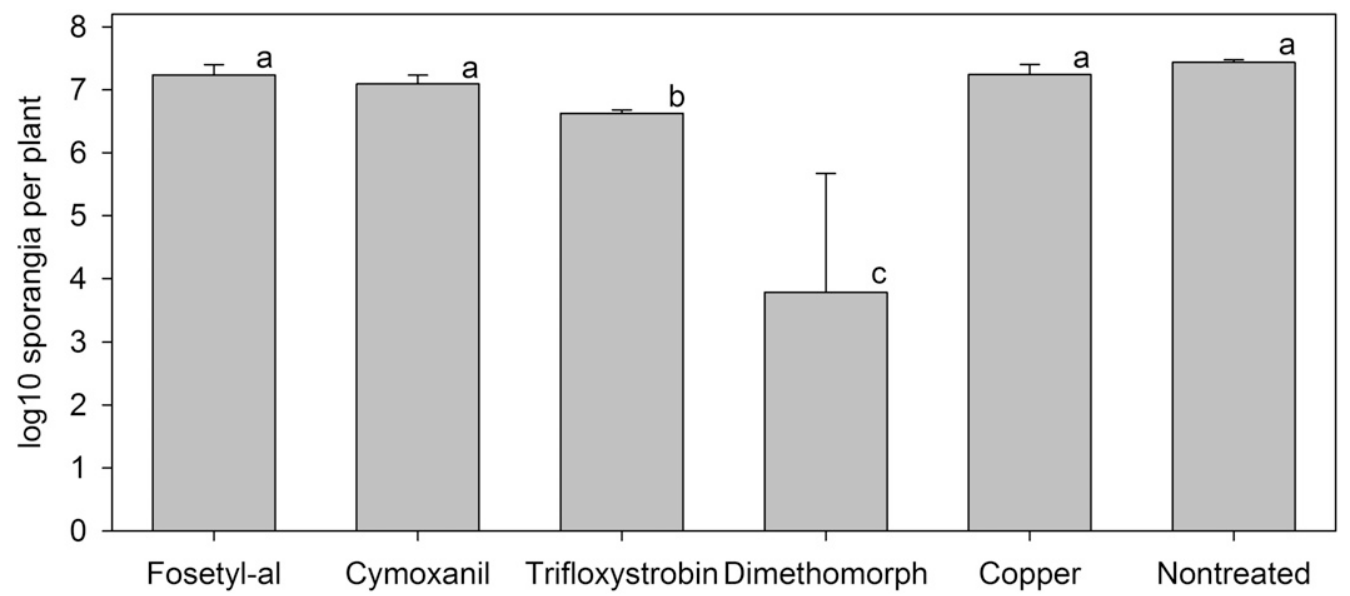

Fig. 2. Number of sporangia of Pseudoperonospora humuli produced on plants 7 days after inoculation when treated with various fungicides $72 \mathrm{~h}$ after inoculation. Bars indicate means and standard errors from four runs of the experiment. Values sharing the same letter are statistically similar based on a mixed-model analysis $(\alpha=0.05)$. 
nearer to the time of inoculation or postinoculation. There was only a small decline in efficacy of disease control when fosetyl-Al was applied 6 to 7 days after inoculation as compared with protective applications (Fig. 4A). Trifloxystrobin and dimethomorph had shorter durations of curative activity than fosetyl-Al (Figs. 4 and 5). For instance, 3 days after inoculation, percent disease control was 80, 35, and $65 \%$ for fosetyl-Al, trifloxystrobin, and dimethormorph, respectively. Trifloxystrobin had a brief period of preinfection activity and limited postinfection activity, with maximal disease control when applied within 4 to 5 days before inoculation (Fig. 4B). Application of this fungicide made 1 day after inoculation resulted in only $55 \%$ disease control. Dimethomorph had the longest duration of protective activity: 77\% disease control 7 days preinoculation as compared with $48 \%$ for fosetyl-Al and $32 \%$ for trifloxysborbin (Fig. 5). Percent disease control from dimethomorph diminished progressively with increasing time between inoculation and application of the fungicide, being intermediate to the curative activity of fosetyl-Al and trifloxystrobin (Figs. 4C and 5).

\section{Discussion}

The lack of high levels of host resistance to downy mildew in most hop cultivars (20) and the development and persistence of resistance to phenylamide and phosphonate fungicides $(11,21,25)$ necessitates multiple modes of action and applications of fungicides per season
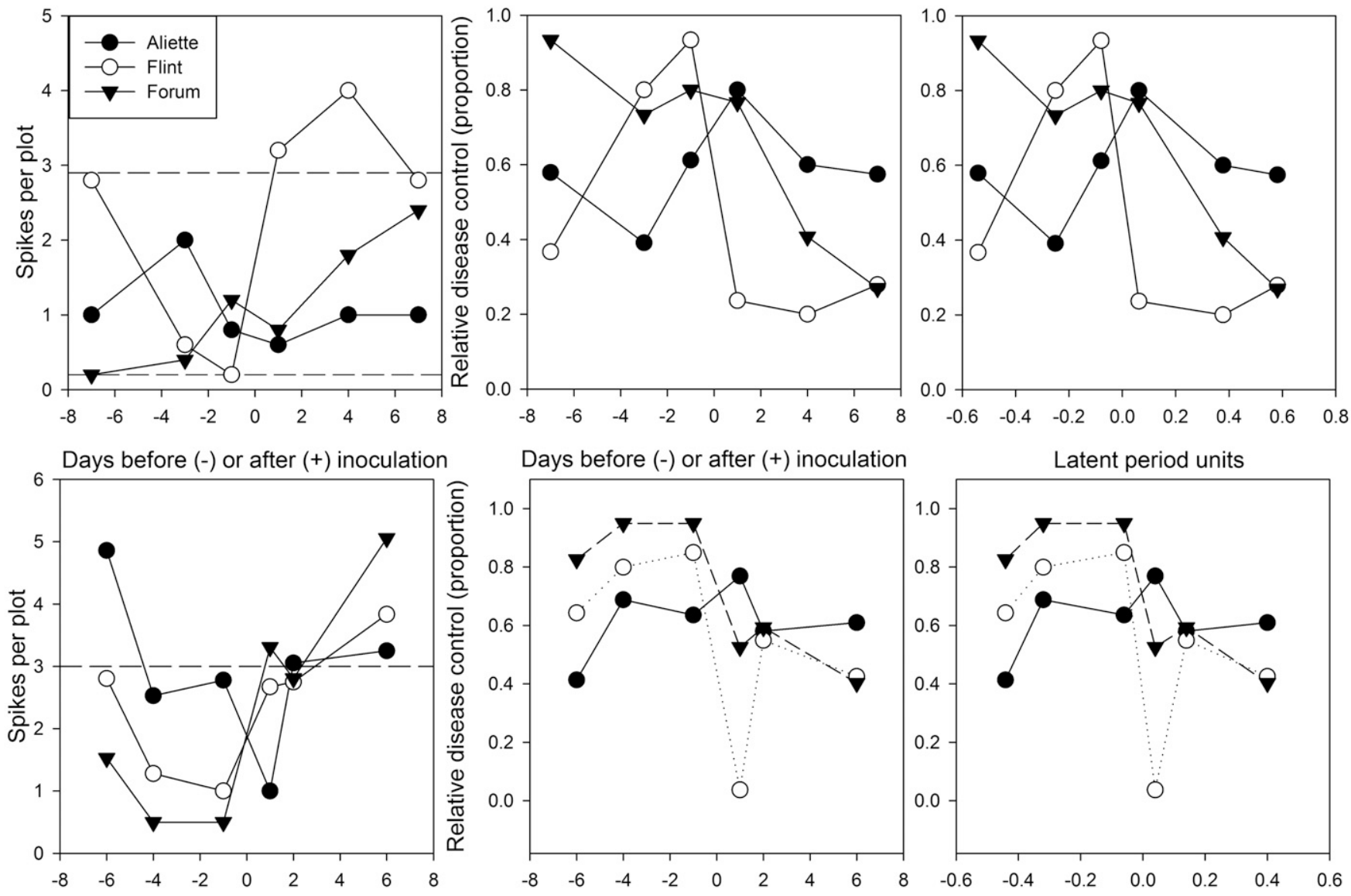

Days before (-) or after (+) inoculation

Days before (-) or after (+) inoculation

Latent period units (proportion)

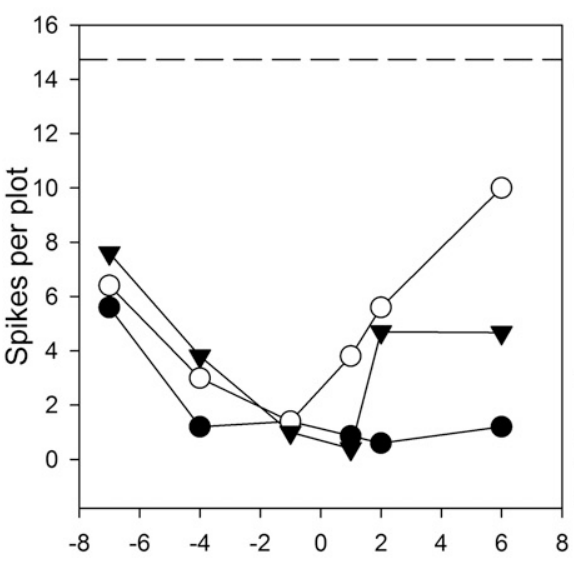

Days before (-) or after (+) inoculation

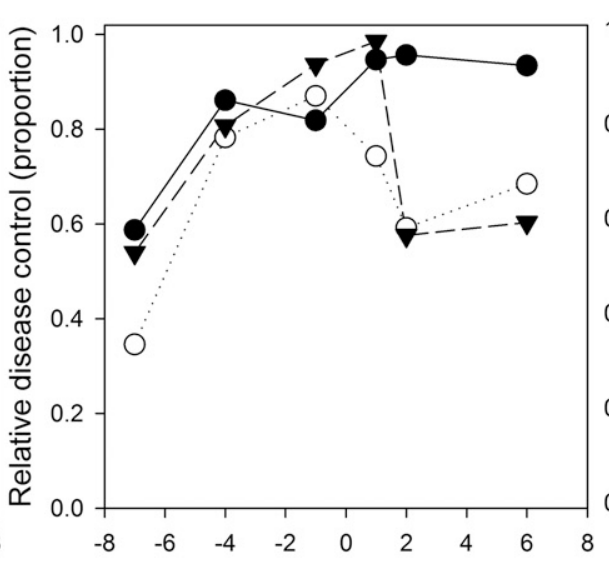

Days before (-) or after (+) inoculation

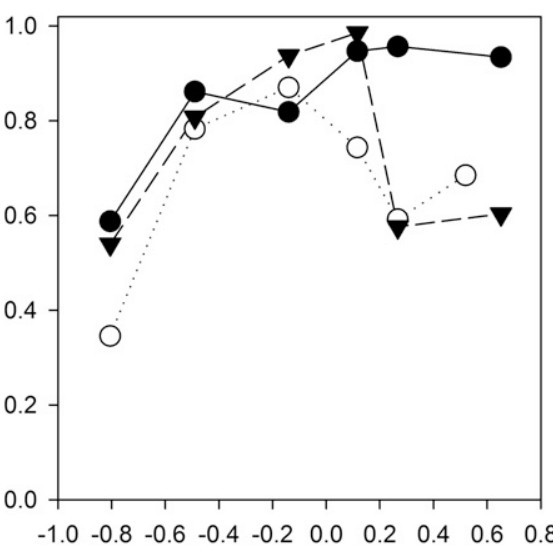

Latent period units (proportion)

Fig. 3. Number of shoots with symptoms of systemic downy mildew (termed "spikes") and relative disease control from three fungicides in relation to application timing. Data are from a pot study in 2012 (top) and 2013 (middle) and a field experiment in 2013 (bottom). Dashed lines in the plots at left indicate the mean number of shoots with downy mildew in nontreated, inoculated plots (top line) and nontreated, noninoculated plots (bottom line in 2012 pot study, 0 in other experiments). 
for adequate control of the disease. The protective and curative activities of fungicides presently used in the management of hop downy mildew vary markedly, and an understanding of physical modes of action is helpful for strategic use of fungicides. In greenhouse experiments, all fungicides evaluated were similarly efficacious when applied just before inoculation. Curative activity varied substantially. Disease control (as measured by leaf area free of sporangiophores) was reduced compared with preventative applications for any postinoculation application timing of copper, or applications made 6, 24, 48 , or $72 \mathrm{~h}$ after inoculation when plants were treated with trifloxystrobin, fosetyl-Al, cymoxanil, and dimethomorph, respectively. Copper and trifloxystrobin had only preinfection fungicidal activity, although the latter fungicide also had antisporulant activity. Similar activity of other fungicides belonging to the quinone outside inhibitor group have been reported for grape downy mildew (35). Curative activity of fosetyl-Al and cymoxanil against $P$. humuli on leaves was similar to that reported by Gisi (15) for other downy mildew diseases. In the current study, dimethomorph had a longer duration of postinfection activity than typically reported for other diseases caused by oomycetes $(3,5,6)$. Some variability in postinfection activity of dimethomorph appears to exist among downy mildew pathogens $(3,6)$, which may reflect differences in absorption and distribution within treated leaves (16). Absorption and distribution may have been maximal during the greenhouse studies because leaf tissue was succulent (to enhance downy mildew susceptibility) and fungicides were applied directly to the abaxial surface of inoculated leaves.

Data from field experiments were somewhat variable, which could be attributable to inherent variability in inoculation and shoot infection, varying growth rates within and among plants, fungicide washoff and weathering, and, potentially, sample sizes. Nonetheless, when applied at labeled rates and a time of year typical of when fungicide applications are made for downy mildew, it is clear that the duration of pre- and postinfection activity varied among fungicides. Trifloxystrobin typically is utilized in commercial hop production in the management of powdery mildew (caused by Podosphaera macuarlis), although trifloxystrobin possesses some activity against downy mildew (24) and is often applied at times when management of both diseases is necessary (12). Control of downy mildew on shoots by trifloxystrobin appears highly sensitive to timing of application. Trifloxystrobin controlled downy mildew on shoots with efficacy similar to that of fosetyl-Al and dimethomorph if applied 4 to 5 days before infection but essentially had no curative activity at the time courses evaluated in this research.

Whereas trifloxystrobin was most effective when applied preventatively, disease control from fosetyl-Al was sensitive to the timing of application before infection. The activity of fosetyl-Al was diminished little when applications were made as long as 7 days after infection. The mode of action of fosetyl-Al and other phosphonate fungicides is complex and pleiotrophic, involving both direct toxicity and stimulation of host defense responses that may affect multiple phases of the pathogen lifecycle and infection process (15). Depending on the pathosystem, phosphonate fungicides may have a relatively long or short period of preventative or curative activity $(1,28,34)$. It is noteworthy that the disease control obtained with fosetyl-Al in the field studies was realized even though plant growth was fairly rapid, with the number of shoots per plant and length of shoots increasing more than twofold during the time course of when fungicide applications were made in a given experiment. Fosetyl-Al is highly mobile within the apoplast and symplast, and the extensive period of postinfection activity may be related to redistribution of fosetyl-Al or its metabolites within treated plants.

Carboxylic acid amide fungicides tend to have strong preventative activity against downy mildews (16) but curative activity typically is restricted to 2 days or less (15). This was generally true of dimethomorph in the field experiments reported here. This fungicide had the greatest duration of preventative activity, and the degree of curative activity diminished rapidly 2 days after inoculation.
Although it is convenient to define the duration of preventative and curative activity of fungicides based on calendar days, expression of time in thermal units may yield better predictions with poikilothermic organisms because developmental rates are dependent on temperature (26). The latent period of downy mildew on shoots in

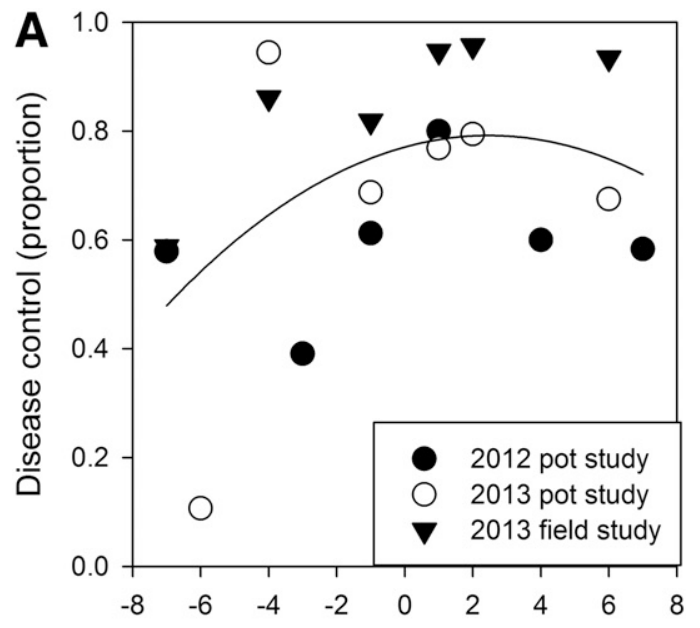

Days before (-) or after (+) inoculation

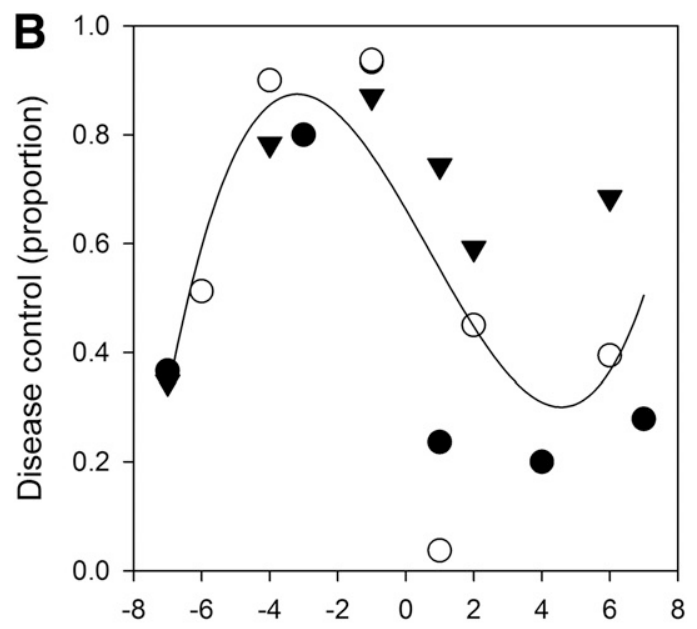

Days before (-) or after (+) inoculation

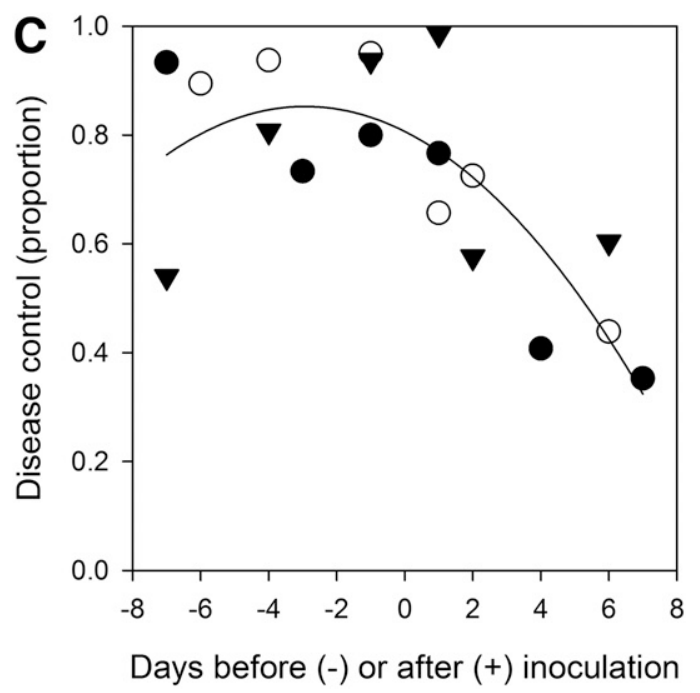

Fig. 4. Control of downy mildew shoot infection on hop with A, fosetyl-Al; B, trifloxystrobin; and $\mathbf{C}$, dimethomorph in relation to fungicide application timing before and after a single inoculation with Pseudoperonospora humuli. Curves in each figure are polynomial mixed-effects models. 
relationship to constant temperature was described previously by Royle (28). With this data, it is possible to fit a simple model, such as the model described by Pfender (26), to quantitatively express latent period duration as a function of temperature. We did this in preliminary analyses and related percent disease control measured in the field studies to latent period units of downy mildew on shoots (Fig. 3 ). The shape of the curves presented in Figure 5 were similar when based on days or latent period units of the pathogen since inoculation, and were not presented for brevity. However, we caution that, under field conditions, duration of preventative and curative activity of fungicides could be influenced by temperature and other factors not accounted for in the present study.

Numerous disease warning systems have been developed for hop downy mildew. Typically, disease hazard warnings are issued in response to measured or forecasted rain coincident with temperatures permissive to infection $(12,29,30)$. In some instances, the quantity or presence of airborne sporangia is used as a component of fungicide application decisions $(10,29)$. In the absence of this information, however, fungicide applications made according to disease warning systems are de facto postinfection applications and, therefore, must contain fungicides with curative activity or be applied to target ensuing secondary cycles of disease. This research has defined the fungicides that may be suitable for both uses. It is less clear whether postinfection applications may hasten the development of fungicide resistance for certain modes of action where resistance management is required, as with carboxylic acid amide products. Few experimental data exist that provide guidance on use of fungicides preventatively versus curatively in a fungicide resistance management context, although current resistance management guidelines discourage use of curative application of fungicides (2). However, depending on the degree of systemic infection of Pseudoperonospora humuli present in a hop yard fungicide applications may, in fact, always act on the pathogen postinfection. Nonetheless, the research presented here may suggest appropriate tank mixes of fungicides to maximize the duration of disease control. For instance, the physical modes of action of phosphonate and carboxylic acid amide fungicides appear complementary and tank mixes of these products may be suitable for both resistance management considerations and extending intervals between applications.

\section{Acknowledgments}

Funding for these studies was provided by the Oregon State University Agricultural Research Foundation, Oregon Hop Commission, and USDA-ARS CRIS Project 5358-21000-035-00. We thank D. Johnson and C. Ocamb for providing helpful suggestions that improved the manuscript; and S. Massie, Capital Farms,

Table 1. Estimates for fixed effects of time before or after a fungicide application (days) on proportion of control of hop downy mildew on shoots ${ }^{\mathrm{a}}$

\begin{tabular}{|c|c|c|c|c|c|c|}
\hline Fungicide & Effect & Estimate & Standard error & DF & $t$ Value & $P$ value \\
\hline \multirow[t]{3}{*}{ Fosetyl-Al } & Intercept & 0.7706 & 0.08616 & 2.8 & 8.94 & 0.0037 \\
\hline & Days & 0.01723 & 0.007932 & 65.6 & 2.17 & 0.0335 \\
\hline & Days $\times$ days & -0.00348 & 0.001834 & 65.7 & -1.90 & 0.0619 \\
\hline \multirow[t]{4}{*}{ Trifloxystrobin } & Intercept & 0.666 & 0.0635 & 5.1 & 10.49 & 0.0001 \\
\hline & Days & -0.1109 & 0.0252 & 64.6 & -4.41 & $<0.0001$ \\
\hline & Days $\times$ days & -0.00605 & 0.0022 & 65.6 & -2.80 & 0.0066 \\
\hline & Days $\times$ days $\times$ days & 0.002394 & 0.0006 & 65.0 & 3.76 & 0.0004 \\
\hline \multirow[t]{3}{*}{ Dimethomorph } & Intercept & 0.8065 & 0.03879 & 25.9 & 20.79 & $<0.0001$ \\
\hline & Days & -0.03139 & 0.007893 & 67.9 & -3.98 & 0.0002 \\
\hline & Days $\times$ days & -0.00536 & 0.001825 & 65.7 & -2.94 & 0.0046 \\
\hline
\end{tabular}

\footnotetext{
a Relative disease control from the three fungicides in relationship to timing of fungicide application before or after a single inoculation (termed "days") was determined in three field experiments during 2012 and 2013. Experiment, block nested with experiment, and the interaction of days $\times$ experiment were considered random factors in the analysis. Polynomial terms for days before or after inoculation were selected based on significance of the terms in the model and residual diagnostics.
}

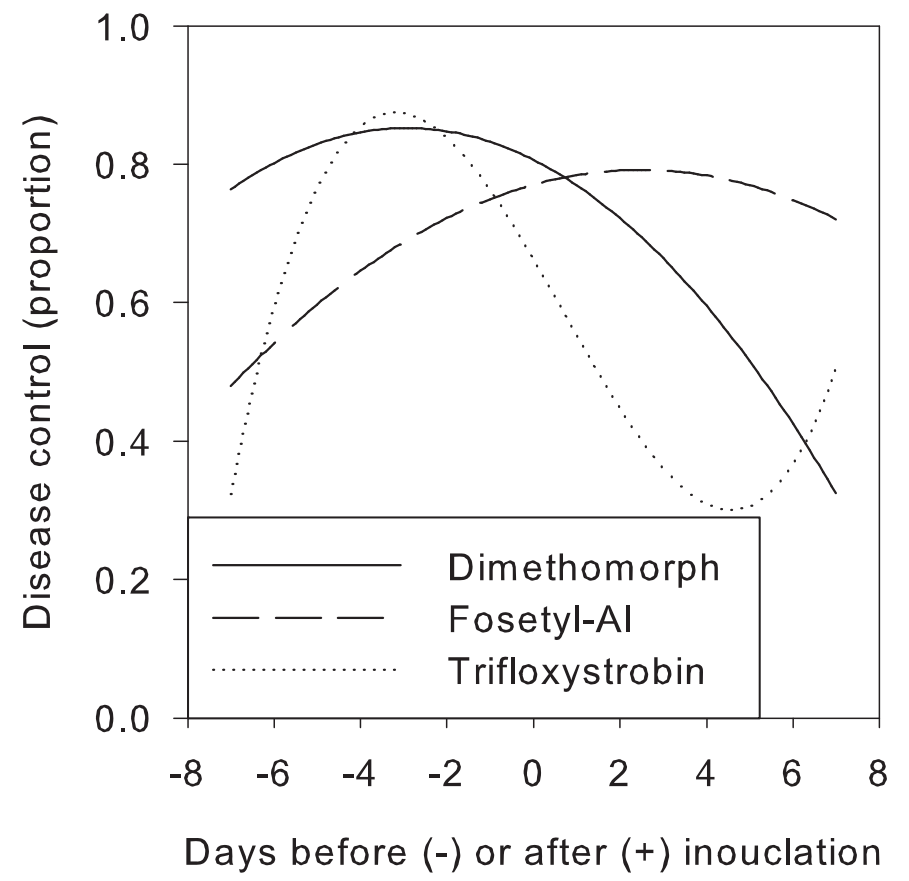

Fig. 5. Comparison of disease control with fosetyl-Al, trifloxystrobin, and dimethomorph in relation to timing of application. 
and $\mathrm{F}$ and $\mathrm{B}$ Nursery for providing the time, resources, and facilities that made this work possible.

\section{Literature Cited}

1. Aegerter, B. J., Nuñez, J. J., and Davis, R. M. 2002. Detection and management of downy mildew in rose rootstock. Plant Dis. 86:1363-1368.

2. Brent, K. J., and Hollomon, D. W. 2007. Fungicide Resistance in Crop Pathogens: How Can It Be Managed? FRAC Monograph No. 1. Croplife International, Brussels, Belgium.

3. Cohen, Y., Baider, A., and Cohen, B.-H. 1995. Dimethomorph activity against oomycete fungal plant pathogens. Phytopathology 85:1500-1506.

4. Cohen, Y., and Coffey, M. D. 1986. Systemic fungicides and the control of oomycetes. Annu. Rev. Phytopathol. 24:311-338.

5. Cohen, Y., and Gisi, U. 2007. Differential activity of carboxylic acid amide fungicides against various developmental stages of Phytophthora infestans. Phytopathology 97:1274-1283.

6. Cohen, Y., Rubin, A., and Gotlieb, D. 2008. Activity of carboxylic acid amide (CAA) fungicides against Bremia lactucae. Eur. J. Plant Pathol. 122:169-183.

7. Coley-Smith, J. R. 1962. Overwintering of hop downy mildew Pseudoperonospora humuli (Miy. and Tak.) Wilson. Ann. Appl. Biol. 50:235-243.

8. Coley-Smith, J. R. 1964. Persistence and identification of downy mildew Pseudoperonospora humuli (Miy. and Tak.) Wilson in hop rootstocks. Ann. Appl. Biol. 53:129-132.

9. Coley-Smith, J. R. 1965. Infection of hop rootstocks by downy mildew Pseudoperonospora humuli (Miy. et Tak.) Wilson and its control by earlyseason dusts. Ann. Appl. Biol. 56:381-388.

10. Gent, D. H., Nelson, M. E., Farnsworth, J. L., and Grove, G. G. 2009. PCR detection of Pseudoperonospora humuli in air samples from hop yards. Plant Pathol. 58:1081-1091.

11. Gent, D. H., Nelson, M. E., and Grove, G. G. 2008. Persistence of phenylamide insensitivity in Pseudoperonospora humuli. Plant Dis. 92:463-468.

12. Gent, D. H., Ocamb, C. M., and Farnsworth, J. L. 2010. Forecasting and management of hop downy mildew. Plant Dis. 94:425-431.

13. Gent, D. H., Mahaffee, W. F., McRoberts, N., and Pfender, W. F. 2013. The use and role of predictive systems in disease management. Annu. Rev. Phytopathol. 51:267-89.

14. Gent, D. H., Nelson, M. E., Grove, G. G., Mahaffee, W. F., Turechek, W. W., and Woods, J. L. 2012. Association of spring pruning practices with severity of powdery mildew and downy mildew on hop. Plant Dis. 96:1343-1351.

15. Gisi, U. 2002. Chemical control of downy mildews. Pages 119-159 in: Advances in Downy Mildew Research. N. T. E. Spencer-Phyllips, U. Gisi, and A. Lebeda, eds. Kluwer Academic Press, Dordrecht, The Netherlands.

16. Gisi, U., Lamberth, C., Mehl, A., and Seitz, T. 2012. Carboxylic acid amide (CAA) fungicides. Pages 807-830 in: Modern Crop Protection Compounds, Volumes 1-3, Second Edition. W. Krämer, U. Schirmer, P. Jeschke, and M. Witschel, eds. Wiley-VCH Verlag GmbH \& Co. KGaA, Weinheim, Germany.

17. Haunold, A., Likens, S. T., Nickerson, G. B., and Hampton, R. O. 1984. Registration of Nugget hop. Crop Sci. 24:1005-1006.

18. Johnson, D. A., and Anliker, W. L. 1985. Effect of downy mildew epidemics on the seasonal carryover of initial inoculum in hop yards. Plant Dis. 69: 140-142.
19. Johnson, D. A., Cummings, T. F., and Geary, B. 2000. Postinfection activity of selected late blight fungicides. Plant Dis. 84:1116-1120.

20. Johnson, D. A., Engelhard, B., and Gent, D. H. 2009. Downy mildew. Pages 18-22 in: Compendium of Hop Diseases and Pests. W. F. Mahaffee, S. J. Pethybridge, and D. H. Gent, eds. American Phytopathological Society, St. Paul, Minnesota.

21. Klein, R. E. 1994. Occurrence and incidence of metalaxyl resistance in Pseudoperonospora humuli in the Pacific Northwest. Plant Dis. 78:161-163.

22. Magarey, P. A., Wachtel, M. F., and Newton, M. R. 1991. Evaluation of phosphonate, fosetyl-Al and several phenylamide fungicides for post-infection control of grapevine downy mildew caused by Plasmopara viticola. Australas. Plant Pathol. 20:34-40.

23. Mitchell, M. N., Ocamb, C. M., Grünwald, N. J., Mancino, L. E., and Gent, D H. 2011. Genetic and pathogenic relatedness of Pseudoperonospora cubensis and $P$. humuli. Phytopathology 101:805-818.

24. Nelson, M., and Grove, G. G. 2009. Evaluation of fungicides for control of hop downy mildew and powdery mildew, 2008. Plant Dis. Manage. Rep. 3:FC008.

25. Nelson, M. E., Eastwell, K. C., Grove, G. G., Barbour, J. D., Ocamb, C. M., and Alldredge, J. R. 2004. Sensitivity of Pseudoperonospora humuli (the casual agent of hop downy mildew) from Washington, Idaho, and Oregon to fosetyl-Al (Aliette). Online publication. Plant Health Prog. 10.1094/PHP2004-0811-01-RS.

26. Pfender, W. F. 2001. A temperature-based model for latent-period duration in stem rust of perennial ryegrass and tall fescue. Phytopathology 91:111-116.

27. Pfender, W. F. 2006. Interaction of fungicide physical modes of action and plant phenology in control of stem rust of perennial ryegrass grown for seed. Plant Dis. 90:1225-1232.

28. Rebollar-Alviter, A., Madden, L. V., and Ellis, M. A. 2007. Pre- and postinfection activity of azoxystrobin, pyraclostrobin, mefenoxam, and phosphite against rot of strawberry, caused by Phytophthora cactorum. Plant Dis. 91: 559-564.

29. Royle, D. J. 1973. Quantitative relationships between infection by the hop downy mildew pathogen, Pseudoperonospora humuli, and weather and inoculum factors. Ann. Appl. Biol. 73:19-30.

30. Royle, D. J., and Kremheller, H. T. H. 1981. Downy mildew of the hop. Pages 395-419 in: The Downy Mildews. D. M. Spencer, ed. Academic Press, New York

31. Skotland, C. B. 1961. Infection of hop crowns and roots by Pseudoperonospora humuli and its relation to crown and root rot and overwintering of the pathogen. Phytopathology 51:241-244.

32. Sudisha, J., Niranjana, S. R., Sukanya, S. L., Girijamba, R., Devi, N. L., and Shetty, H. S. 2010. Relative efficacy of strobilurin formulations in the control of downy mildew of sunflower. J. Pest Sci. 83:461-470.

33. Szkolnik, M. 1978. Techniques involved in greenhouse evaluation of deciduous tree fruit fungicides. Annu. Rev. Phytopathol. 16:103-129.

34. Wicks, T. J., Magarey, P. A., Wachtel, M. F., and Frensham, A. B. 1991 Effect of postinfection applications of phosphorous (phosphonic) acid on the incidence and sporulation of Plasmopara viticola on grapevine. Plant Dis. 75:40-43.

35. Wong, F. P., and Wilcox, W. F. 2001. Comparative physical modes of action of azoxystrobin, mancozeb, and metalaxyl against Plasmopara viticola (grapevine downy mildew). Plant Dis. 85:649-656. 